\title{
Ranibizumab versus Aflibercept in Macular Edema Secondary to Retinal Vein Occlusion in Real Life: A Retrospective Case Control Study
}

\author{
Abdullah Ozkaya, Ruveyde Garip, Ceren Yesilkaya, Zeynep Alkin, Muhittin Taskapili \\ University of Health Sciences Beyoglu Eye Training and Research Hospital, Istanbul, Turkey
}

\begin{abstract}
Objectives: The present study is comparison of efficacy of ranibizumab and aflibercept in the treatment of macular edema (ME) secondary to retinal vein occlusion (RVO) in real life.

Methods: Design was retrospective, case-control study. Treatment naïve RVO patients with ME who were treated with ranibizumab or aflibercept and had minimum follow-up time of 6 months were included. Primary outcome measures were changes in best corrected visual acuity (BCVA) and central retinal thickness (CRT). Secondary outcome measure was number of injections administered.

Results: Mean baseline, month 3, and month 6 BCVA in ranibizumab group was $0.95 \pm 0.6 \mathrm{I}-, 0.50 \pm 0.30-$, and $0.66 \pm 0.58$ logarithm of the minimum angle of resolution (LogMAR), respectively. Mean baseline, month 3, and month 6 BCVA in aflibercept group was $0.85 \pm 0.65-, 0.61 \pm 0.58$-, and $0.65 \pm 0.55$ LogMAR, respectively. Mean baseline, month 3 , and month 6 CRT in ranibizumab group was 598 $189-, 473 \pm 162-$, and $359 \pm 134 \mu \mathrm{m}$, respectively. Mean baseline, month 3, and month 6 CRT in aflibercept group was $5 \mathrm{I} 2 \pm|4|$-, $345 \pm I 54-$, and $374 \pm 172 \mu \mathrm{m}$, respectively. Mean number of injections was $2.7 \pm 0.8$ for ranibizumab group, and $2.2 \pm 1.0$ for aflibercept group $(p=0.08)$.

Conclusion: Ranibizumab and aflibercept are both effective agents in the treatment of ME secondary to RVO. Visit and injection figures were lower than those reported in prospective, multicenter studies, as expected, but functional and anatomical outcomes were comparable.
\end{abstract}

Keywords: Aflibercept, macular edema, ranibizumab, retinal vein occlusion.

\section{Introduction}

Retinal vein occlusion (RVO) is the second most common type of retinal vascular disorder after diabetic retinopathy (I-3). Macular edema (ME) and vitreous hemorrhage are frequent causes of visual loss in cases of RVO $(I-5)$. Both inflammation and increased vascular endothelial growth factor (VEGF) level play important role in pathogenesis of ME secondary to RVO (4-7). Laser photocoagulation, vitreoretinal surgery, intravitreal anti-VEGF and steroid injections, and various surgical techniques have been reported to be effec- tive in treatment of ME secondary to RVO (I-8).Currently, intravitreal injections are particularly preferred as first-line treatment option for ME (8). Bevacizumab, ranibizumab, and aflibercept are the 3 anti-VEGF agents used in treatment. The first drug is used off-label; the others are approved for this purpose $(2,8,9-12)$. In pivotal multicenter studies in which strict follow-up and treatment criteria were observed, successful treatment outcomes have been reported (9-13). However, it is usually not possible to replicate these strict criteria in real-life practice (14-16). Number of injections, especially, has been found to be very low in real-life studies in

Address for correspondence: Abdullah Ozkaya, MD. Beyoglu Goz Egitim ve Arastirma Hastanesi, Bereketzade Cami Sokak, 34421 Beyoglu, Istanbul, Turkey

Phone: +90 2122515900 E-mail: abdozkaya@gmail.com

Submitted Date: January 01, 2017 Accepted Date: March 28, 2017 Available Online Date: May 04, 2017

${ }^{\oplus}$ Copyright 2017 by Beyoglu Eye Training and Research Hospital - Available online at www.beyoglueye.com 
comparison with multicenter research (14-16). In this study, efficacy of ranibizumab and aflibercept in real-life practice were compared.

\section{Methods}

In this retrospective, case-control study, medical records of patients with ME secondary to RVO and who underwent intravitreal ranibizumab (IVR) or aflibercept (IVAfl) treatment between January 2014 and January 2016 were reviewed. Newly diagnosed RVO patients who had ME $<3$ months at first admission were treatment-naïve for $M E$, and had follow-up of at least 6 months were included. Patients who had co-existing retinal disease (e.g., diabetic retinopathy, epiretinal membrane), or media opacities that could decrease visual acuity (VA) were not included. Written informed consent for treatment was obtained from all patients, and the study adhered to the tenets of the Declaration of Helsinki.

Data collected from patient records included age; gender; type of RVO; ischemic status; best corrected visual acuity (BCVA) and central retinal thickness (CRT) at baseline, month 3, and month 6; and number of injections.

All patients underwent standardized examination with measurement of BCVA via Early Treatment Diabetic Retinopathy Study (ETDRS) chart at 4 meters, slit-lamp biomicroscopy and fundus examination, and measurement of intraocular pressure (IOP) via applanation tonometry. Fundus photography, fluorescein angiography (HRA-2; Heidelberg Engineering, Heidelberg, Germany), and optical coherence tomography (OCT) imaging (Spectralis; Heidelberg Engineering, Heidelberg, Germany) were performed before treatment. All examinations were repeated at all of visits, with exception of fluorescein angiography, which was repeated only when cause of VA deterioration could not be clarified in clinical examination or with other imaging methods. OCT was used to measure CRT, which was defined as mean thickness of neurosensory retina in central $\mathrm{I} \mathrm{mm}$ diameter region, and was computed via OCT mapping software provided with the device. Fluorescein angiography was inspected for capillary drop-out zones at the fovea and peripheral retina and leaking areas, which were accepted as cause of ME. Type of disease was defined as ischemic RVO, if there was ischemic area $\geq 5$ disc areas in branch retinal vein occlusion (BRVO) patients, and $\geq 10$ disc areas in central retinal vein occlusion (CRVO) patients.

All injections were performed under sterile conditions after topical anesthesia, 10\% povidone-iodine (Betadine; Purdue Pharma, Stamford, CT, USA) scrub was used on the eyelids and eyelashes, and $5 \%$ povidone-iodine was administered on the conjunctival sac. Intravitreal ranibizumab 0.5 $\mathrm{mg} / 0.5 \mathrm{~mL}$ (Lucentis; Novartis, Basel, Switzerland) or aflibercept 2 mg/0.5 mL (Eylea; Bayer, Berlin, Germany) was inject-
Table I. General characteristics of the patients

\begin{tabular}{lc} 
Age (years) & $56.6 \pm 1 \mathrm{I} .7$ \\
Gender (male/female) & $18 / 27$ \\
Hypertension (\%) & $34(75.5)$ \\
Diabetes (\%) & $1 \mathrm{I}(24.4)$ \\
Hyperlipidemia (\%) & $5(1 \mathrm{I} .1)$ \\
Fluoroscein angiography (non-ischemic/ischemic) & $33 / 12$ \\
Type of RVO (BRVO/CRVO) & $38 / 8$ \\
Lens status (phakic/pseudophakic) & $37 / 8$ \\
Baseline BCVA (Snellen) & $0.27 \pm 0.27$ \\
Baseline CRT ( $\mu \mathrm{m})$ & $58 \mathrm{I} \pm 188$ \\
\hline
\end{tabular}

BCVA: best corrected visual acuity; BRVO: branch retinal vein occlusion; CRT: central retinal thickness; CRVO: central retinal vein occlusion; RVO: retinal vein occlusion.

ed through the pars plana at $3.5 \mathrm{~mm}$ posterior to the limbus with 30-gauge needle. Patients were instructed to return to the hospital if they experienced decreased vision, eye pain, or any new symptoms.

Initially, some patients received loading dose of 3 consecutive monthly injections. There were no strict criteria for administering loading dose. Then, patients were followed monthly, and single IVA or IVAfl injection was repeated when VA decreased by one or more ETDRS lines from previous visit, or any increase in CRT in OCT images was observed.

Primary outcome measures of this study were change in BCVA and CRT. Secondary outcome measure was number of injections administered.

\section{Statistical Analysis}

VA was converted to the logarithm of the minimum angle of resolution (LogMAR) for statistical analysis. Categorical variables were presented as numbers and percentages, while numerical variables were expressed as mean and SD. First, data were analyzed in terms of normality using Shapiro-Wilk test. As the distribution of the data was found to be normal, independent sample t-test was used to compare numerical variables between the 2 groups. Change in VA within the 2 treatment groups was assessed with paired samples t-test. Categorical variables were compared using chi-square test. $\mathrm{P}$ value $<0.05$ was considered statistically significant.

\section{Results}

Total of 49 eyes of 49 patients were included. Twenty-seven patients were treated with IVR and 22 patients were treated with IVAfl. Baseline general characteristics were similar between the 2 groups (Table I).

Mean BCVA at baseline, month 3, and month 6 in IVR group was 0.95 \pm 0.61 LogMAR (range: 2.0-0.1 LogMAR), 


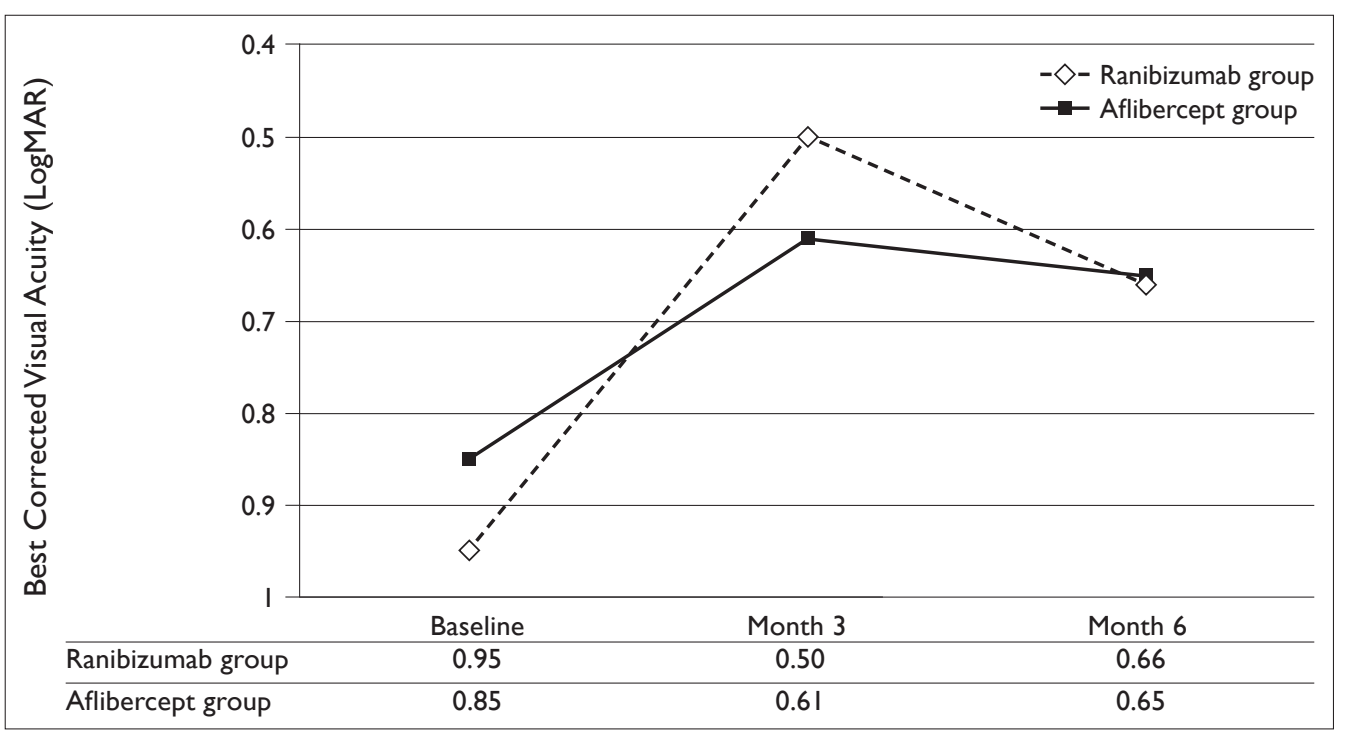

Figure I. The changes in mean visual acuity (VA) in ranibizumab and aflibercept groups. The graph shows the mean logarithm of the minimum angle of resolution VA levels from baseline to month 6. The mean VA levels were not statistically different between the 2 groups at different time points.

$0.50 \pm 0.30$ LogMAR (range: I.0-0.0 LogMAR), and 0.66 \pm 0.58 , respectively. Mean baseline, month 3 , and month 6 BCVA in IVAfl group was $0.85 \pm 0.65$ LogMAR (range: $2.0-0.1$ LogMAR), 0.6I \pm 0.58 LogMAR (range: 2.0-0.0 LogMAR), and 0.65 \pm 0.55 LogMAR (range: 2.0-0.0 LogMAR), respectively (Figure I). Mean BCVA from baseline to months 3 and 6 was statistically better in IVR group $(p=0.0$ I for month 3 ; $p=0.003$ for month 6); however, there was not a significant difference in IVAfl group $(p=0.2$ for month 3 ; and $p=0.1$ for month 6). Change in BCVA from baseline to month 3 and month 6 was not statistically different between the 2 groups ( $p=0.8$ for month 3; $p=0.4$ for month 6). At month $6, \mathrm{II}$ of the 27 patients (40.7\%) in IVR group and 5 of the 22 patients $(22.7 \%)$ in IVAfl group gained VA $\geq 3$ lines $(p=0.3)$. Rate of patients who had stable VA (lost $<3$ lines, stable, or gained $<3$ lines) at month 6 was $51.9 \%(14 / 27)$ in IVR group, and $72.7 \%$ $(16 / 22)$ in IVAfl group, respectively $(p=0.3)$. Only 2 patients $(7.4 \%)$ in IVR group and I patient $(4.5 \%)$ in the IVAfl group lost $\geq 3$ lines of VA at month $6(p=0.3)$.

Mean baseline, month 3, and month 6 CRT in IVR group was $598 \pm 189 \mu \mathrm{m}$ (range: $300-886 \mu \mathrm{m}$ ), $473 \pm 162 \mu \mathrm{m}$ (range:

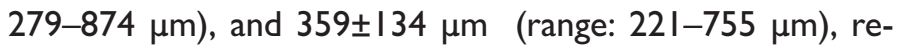
spectively. Mean baseline, month 3, and month 6 CRT in IVA-

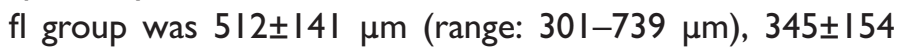
$\mu \mathrm{m}$ (range: $200-710 \mu \mathrm{m}$ ), and 374 $\pm 172 \mu \mathrm{m}$ (range: 204-674 $\mu \mathrm{m}$ ), respectively (Figure 2). The change in CRT from baseline to month 3 was not statistically better in IVR group $(p=0.1)$; however, at month 6 there was a statistically significant reduction from baseline $(p<0.000 \mathrm{I})$.

Change in CRT was statistically better in both month 3 $(p=0.004)$ and month $6(p=0.0 I)$ in IVAfl group. Change in
CRT from baseline to month 3 and month 6 was not statistically different between the 2 groups $(p=0.3$ for month 3; $p=0.1$ for month 6). At month 6, II of the 27 patients $(40.7 \%)$ in IVR group and 8 patients $(36.4 \%)$ in IVAfl group had $C R T<350 \mu \mathrm{m}$ and did not require re-injection at the time $(p=0.9)$.

Mean number of planned visits at month 6 was $2.5 \pm 0.6$ (range: $2-5$ ) for IVR group and 3.4 \pm 0.6 (range: $3-5$ ) for IVAfI group $(p<0.000 \mathrm{I})$, and number of completed visits was

$2.5 \pm 0.6$ (range: $2-5)$ for IVR group (100\% completion), and $3.3 \pm 0.7$ (range: $2-5$ ) for IVAfl group ( $97.3 \%$ completion) $(p<0.00$ I for planned visits; $p>0.8$ for visits completed). Mean number of planned injections at month 6 was $2.8 \pm 0.7$ (range: I-4) in IVR group and 2.4 \pm I.I (range: I-6) in IVAfI group $(p=0.00 \mathrm{I})$, and number of injections performed was $2.7 \pm 0.8$ (range: I-4) for IVR group $(96.0 \%$ completion), and $2.2 \pm 1.0$ (range: $1-5)$ for IVAfl group ( $92.5 \%$ completion) $(p=0.08$ for planned injections, $p=0.2$ for injections completed). Fourteen patients (5I.9\%) in IVR group, and 10 patients (45.5\%) in IVAfl group received loading dose of 3 consecutive monthly injections $(p=0.7)$.

No injection related endophthalmitis was noted after total of 122 injections.

\section{Discussion}

In this study we evaluated 6 months of real-life outcomes of IVR and IVAfl treatment of ME secondary to RVO. Baseline VA increased significantly in IVR group at both month 3 and month 6. Increase was 4.5 LogMAR lines at month 3 , and 2.9 lines at month 6 . Change in VA was not found to be significant in IVAfl group. Increase was 2.4 lines at 


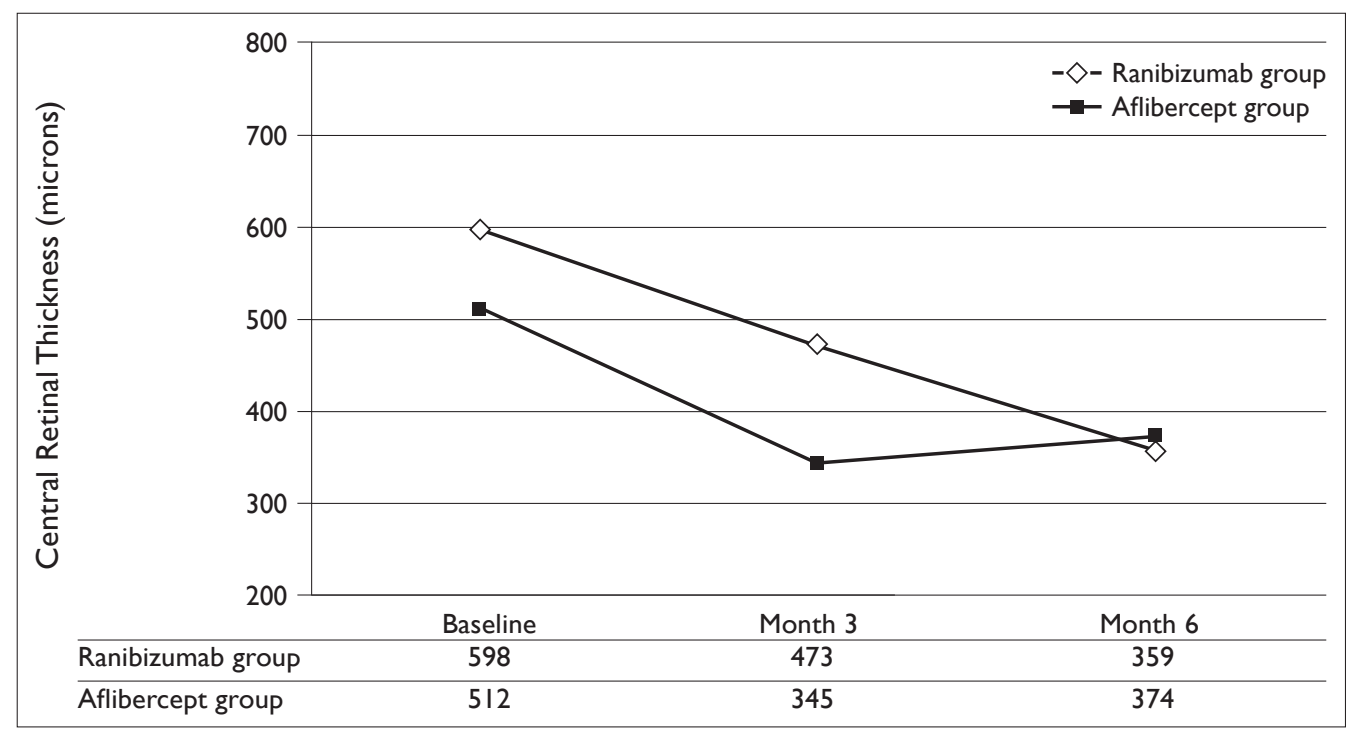

Figure 2. The changes in mean central retinal thickness (CRT) in ranibizumab and aflibercept groups. The graph shows the mean CRT levels from baseline to month 6. The mean CRT levels were not statistically different between the 2 groups at different time points.

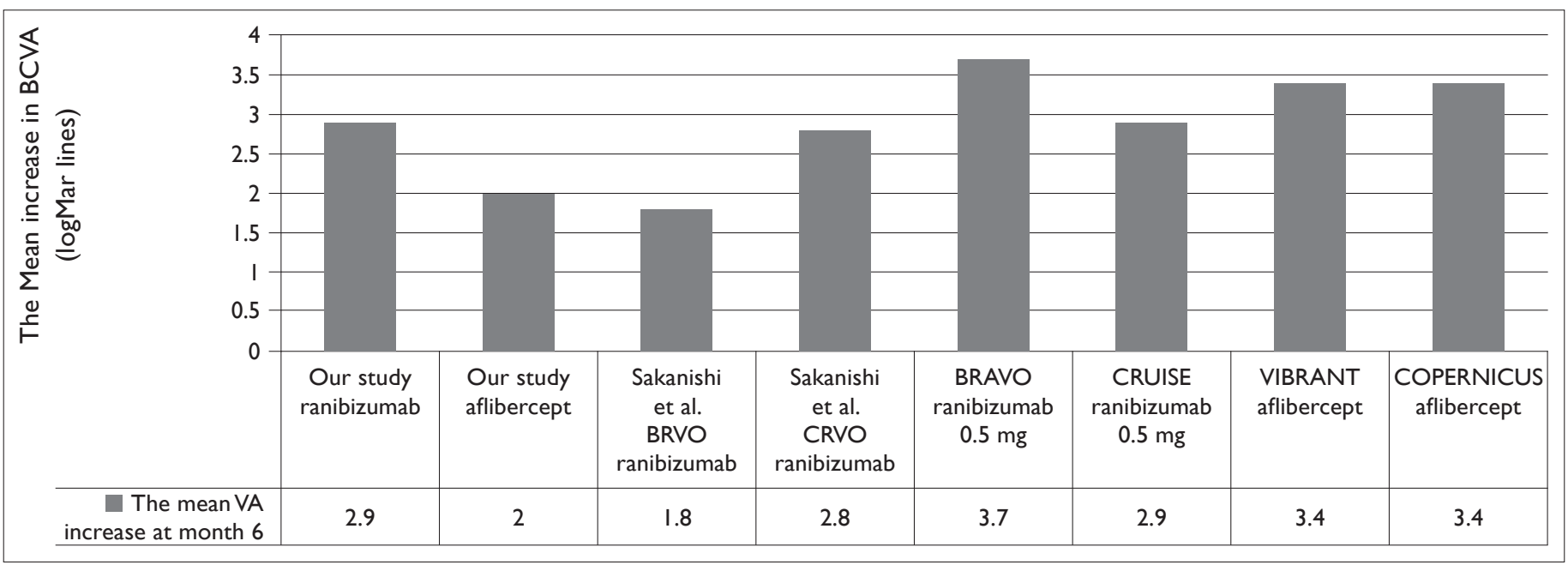

Figure 3. The mean visual acuity levels at month 6 as reported in various studies. Sakanishi et al., reference I6; BRAVO, reference 9; CRUISE, reference 10; VIBRANT, reference 13; COPERNICUS, reference I2.

month 3, and 2 lines at month 6. Change in VA was not statistically significantly different between groups. In a study conducted by Wai et al., it was demonstrated that patients with lower VA (between 20/50 and 20/300) gained more letters than patients with higher VA $(\geq 20 / 40)$ ( 17$)$. In our study, baseline VA, although not statistically significant, was slightly better (I line) in IVAfl group. This may, in part, explain non-significance in IVAfl group with respect to change in VA at month 12.

Change in mean CRT was not statistically significant at month 3 in IVR group; however, there had been dramatic change at month 6 and change had become significant. CRT change in IVAfl group showed significant improvement at month 3 and month 6 . Again, there was no significant differ- ence with regard to CRT change at months 3 and 6 between the 2 groups. Rate of active ME was similar in both groups: around $60 \%$. That is, $40 \%$ of the patients had inactive ME at month 6 .

Mean number of scheduled injections was similar in both groups: 2.8 in IVR group, and 2.4 in IVAfl group, which were both lower than seen in prospective multicenter studies (9-13). In pivotal studies that evaluated IVR and IVAfl in cases of ME secondary to RVO, 6 initial monthly injections were performed (9-12). Subsequently, various treatment regimens were pursued (9-13).Loading phase of anti-VEGF drugs has been investigated in some studies, and low-frequency ranibizumab treatment was found to be effective (I5). It is worth recalling here that 
in real-life setting, it is not always possible to conform to strict follow-up and treatment criteria (I4-20). Low visit and injection frequency observed in real life usually leads to decrease in visual and anatomical outcomes in the patients with neovascular age-related macular degeneration (nAMD) or diabetic macular edema (DME) $(18,19)$. This is not necessarily the case, however, for ME secondary to RVO, which is not usually chronic disease like DME and nAMD $(4-6,21)$. In a prospective study performed by Miwa et al., 81 eyes with ME secondary to branch RVO were evaluated (I5). Some of the patients received loading dose of 3 monthly IVR injections, while some did not and were treated with pro re nata treatment regimen during 12-month follow-up period. At conclusion of the follow-up period, the 2 groups had similar results in visual outcomes. Skanishi et al. evaluated low frequency IVR treatment in ME secondary to RVO, and after a follow-up of 12 months, they reported that patients received mean of 3.4 injections in CRVO group, and 2.1 in BRVO group, which was, again, very low in comparison to multicenter studies (16). Although number of injections was very low, change in VA from baseline to month 6 was reported to be 2.8 lines, and 2.5 lines at month 12 in CRVO group, and 1.8 lines at month 6, and 2.I lines at month 12 in BRVO group, which were comparable outcomes to aforementioned studies (Figure 3) (9-13, 16). In our study, we evaluated BRVO and CRVO patients together and obtained similar results at month 6 in both IVR and IVAfl groups.

The main limitation of this study was retrospective design and small number of patients. Also, some participants received initial 3 monthly doses of IVR, whereas others did not. However, study included only treatment-naïve patients, and was first study (from PubMed search in August 2016) to compare efficacy of IVR and IVAfl and include real-life practice data.

In conclusion, ranibizumab and aflibercept are both effective agents in treatment of ME secondary to RVO. Ranibizumab seemed to be more effective with regard to visual outcomes, and aflibercept seemed to be more effective in terms of anatomical outcomes, though statistically significant difference was not found. Visit and injection numbers were lower than reported in prospective multicenter studies, as expected, but functional and anatomical outcomes were comparable.

\section{Disclosures}

Financial support: No financial support was received for this submission.

Peer-review: Externally peer-reviewed.

Conflict of Interest: None declared.

Authorship Contributions: Involved in design and conduct of the study (AO, RG, CY, ZA, MT); preparation and review of the study (AO, ZA, MT); data collection (AO, RG, CY); and statistical analysis (AO).

\section{References}

I. Scott IU, VanVeldhuisen PC, Oden NL, Ip MS, Blodi BA, Jumper JM, et al. SCORE Study report I: baseline associations between central retinal thickness and visual acuity in patients with retinal vein occlusion. Ophthalmology 2009; I 16:504-12. [CrossRef]

2. Donati S, Barosi P, Bianchi M, Al Oum M, Azzolini C. Combined intravitreal bevacizumab and grid laser photocoagulation for macular edema secondary to branch retinal vein occlusion. Eur J Ophthalmol 2012;22:607-14. [CrossRef]

3. The Branch Vein Occlusion Study Group. Argon laser photocoagulation for macular edema in branch vein occlusion. Am J Ophthalmol 1984;98:27I-82. [CrossRef]

4. Augustin AJ, Sahel JA, Cerulli L, Texier-Richard B, Buchholz PM, Kobelt G. Treating retinal vein occlusions in France, Germany, and Italy: an analysis of treatment patterns, resource consumption, and costs. Eur J Ophthalmol 20I2;22:776-84. [CrossRef]

5. Bhagat N, Goldberg MF, Gascon P, Bell W, Haberman J, Zarbin MA. Central retinal vein occlusion: review of management. Eur J Ophthalmol 1999;9:165-80.

6. Glacet-Bernard A, Coscas G, Zourdani A, Soubrane G, Souied $\mathrm{EH}$. Steroids and macular edema from retinal vein occlusion. Eur J Ophthalmol 20I I;2I Suppl 6:S37-44. [CrossRef]

7. Noma H, Funatsu H, Mimura T, Hori S. Changes of vascular endothelial growth factor after vitrectomy for macular edema secondary to retinal vein occlusion. Eur J Ophthalmol 2008; 18:1017-9.

8. Yumusak E, Buyuktortop N, Ornek K. Early results of dexamethasone implant, ranibizumab, and triamcinolone in macular edema due to branch retinal vein occlusion. Eur J Ophthalmol 2016;26:54-9. [CrossRef]

9. Brown DM, Campochiaro PA, Bhisitkul RB, Ho AC, Gray S, Saroj N, et al. Sustained benefits from ranibizumab for macular edema following branch retinal vein occlusion: 12-month outcomes of a phase III study. Ophthalmology 20 I I; I I 8: I594-602.

10. Brown DM, Campochiaro PA, Singh RP, Li Z, Gray S, Saroj $\mathrm{N}$, et al; CRUISE Investigators. Ranibizumab for macular edema following central retinal vein occlusion: six-month primary end point results of a phase III study. Ophthalmology 2010; I 17: I 124-33. [CrossRef]

I I. Holz FG, Roider J, Ogura Y, Korobelnik JF, Simader C, Groetzbach G, et al. VEGF Trap-Eye for macular oedema secondary to central retinal vein occlusion: 6-month results of the phase III GALILEO study. Br J Ophthalmol 2013;97:278-84. [CrossRef]

I2. Brown DM, Heier JS, Clark WL, Boyer DS, Vitti R, Berliner AJ, et al. Intravitreal aflibercept injection for macular edema secondary to central retinal vein occlusion: I-year results from the phase 3 COPERNICUS study. Am J Ophthalmol 20I 3; I 55:429_ 37. [CrossRef]

13. Clark WL, Boyer DS, Heier JS, Brown DM, Haller JA, Vitti R, et al. Intravitreal Aflibercept for Macular Edema Following Branch 
Retinal Vein Occlusion: 52-Week Results of the VIBRANT Study. Ophthalmology 2016;123:330-6. [CrossRef]

14. Ozkaya A, Celik U, Alkin Z, Faiz Turan M, Yazici AT, Demirok A. Comparison between Intravitreal Triamcinolone with Grid Laser Photocoagulation versus Bevacizumab with Grid Laser Photocoagulation Combinations for Branch Retinal Vein Occlusion. ISRN Ophthalmol 2013;2013:14I279. [CrossRef]

I5. Miwa Y, Muraoka Y, Osaka R, Ooto S, Murakami T, Suzuma K, et al. Ranibizumab FOR MACULAR EDEMA AFTER BRANCH RETINAL VEIN OCCLUSION: One Initial Injection Versus Three Monthly Injections. Retina 2017;37:702-9. [CrossRef]

16. Sakanishi Y, Lee A, Usui-Ouchi A, Ito R, Ebihara N. Twelvemonth outcomes in patients with retinal vein occlusion treated with low-frequency intravitreal ranibizumab. Clin Ophthalmol 2016; I0: I |6I-5. [CrossRef]

17. Wai KM, Khan M, Srivastava S, Rachitskaya A, Silva FQ, Deasy $R$, et al. Impact of initial visual acuity on anti-VEGF treatment outcomes in patients with macular oedema secondary to reti- nal vein occlusions in routine clinical practice. $\mathrm{Br} J$ Ophthalmol $2016 ; 308727$.

18. Vorum H, Olesen TK, Zinck J, Størling Hedegaard M. Real world evidence of use of anti-VEGF therapy in Denmark. Curr Med Res Opin 2016;32:1943-50. [CrossRef]

19. Holz FG, Tadayoni R, Beatty S, Berger AR, Cereda MG, Hykin P, et al. Determinants of visual acuity outcomes in eyes with neovascular AMD treated with anti-VEGF agents: an instrumental variable analysis of the AURA study. Eye (Lond) 2016;30:10637I. [CrossRef]

20. Ozkaya A, Alkin Z, Yesilkaya C, Erdogan G, Perente I, Taskapili M. Ranibizumab in macular edema secondary to retinal vein occlusion in a real life practice: A retrospective case series. Beyoglu Eye J 2016;1:5-9. [CrossRef]

2I. Branch Vein Occlusion Study Group. Argon laser scatter photocoagulation for prevention of neovascularization and vitreous hemorrhage in branch vein occlusion. A randomized clinical trial. Arch Ophthalmol 1986; 104:34-4I. [CrossRef] 